\title{
IDENTIFICATION AND CHARACTERIZATION OF PARASITE NEOPHARYNGODON SP. FROM WALL LIZARD (GECKO) OF NEPAL
}

\section{Shyam K. Pun and Mahendra Maharjan}

Journal of Institute of Science and Technology

Volume 21, Issue 1, August 2016

ISSN: 2469-9062 (print), 2467-9240(e)

Editors:

Prof. Dr. Kumar Sapkota

Prof. Dr. Armila Rajbhandari

Assoc. Prof. Dr. Gopi Chandra Kaphle

JIST, 21 (1), 52-55 (2016)

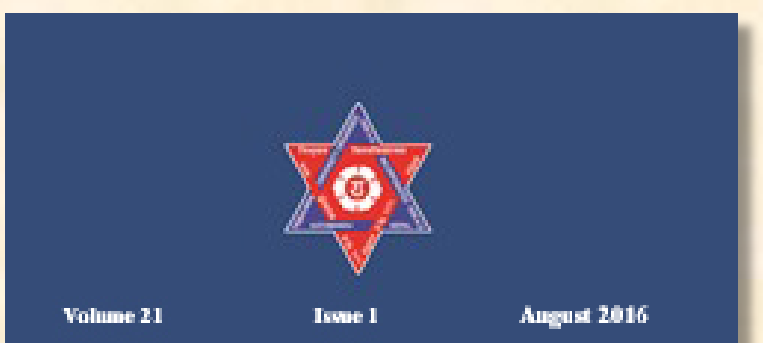

JOURNAL OF INSTITUTE OF SCIENCE AND TECHNOLOGY
Published by

Institute of Seience and Teehnology

Tribhuvan University

Kirtipur, Kathmanda, Nepal

Published by:

Institute of Science and Technology

Tribhuvan University

Kirtipur, Kathmandu, Nepal 


\title{
IDENTIFICATION AND CHARACTERIZATION OF PARASITE NEOPHARYNGODON SP. FROM WALL LIZARD (GECKO) OF NEPAL
}

\author{
Shyam K. Pun and Mahendra Maharjan* \\ Central Department of Zoology, Tribhuvan University, Kirtipur, Nepal \\ "Corresponding email: mmaharjan@cdztu.edu.np
}

\begin{abstract}
A total of 25 wall lizards (15 Hemidactylus brookii brookii and $10 \mathrm{H}$. platyurus) were examined for nematode parasite Neopharyngodon sp. from Kirtipur, Nepal. Neopharyngodon sp. were taxonomically identified and showed characteristics like small size $(1.375-1.5 \mathrm{~mm} \times 0.225-0.25 \mathrm{~mm})$, mouth with two lips, oesophagus $(0.35 \mathrm{~mm} \times 0.03 \mathrm{~mm})$, oesophagus bulb $(0.092 \mathrm{~mm})$ and pointed tail with size one-third of the whole body length. Twenty percent of $H$. brookii brookii harbored the nematode parasite with average parasitic intensity of 4.3 while $80 \%$ of $H$. platyrus showed Neopharyngodon sp with parasitic intensity of 4 .
\end{abstract}

Keywords: Neopharyngodon sp., Nematode, Hemidactylus brookii brookii, Hemidactylus platyurus

\section{INTRODUCTION}

Nepal is a biodiversity rich country. As far as present knowledge is concerned, there are four genera and 10 species of geckos belonging to family Gekkonidae in Nepal (Shah \& Tiwari 2004). Hemidactylus brookii brookii (Fig. 1A) and Hemidactylus platyurus (Fig. 1B) are the commonly distributed house lizards of Terai and hills of Nepal. Less information is available regarding the parasites of amphibians and reptiles. However, recently herpeto fauna parasites Rhabdias sp. and Aplectana in toads (Pun \& Maharjan 2015 \& 2016b), and Kalicephalus sp. in snakes have been reported (Pun \& Maharjan 2016a). Nematode subfamily cosmocercinae includes two genera: Neopharyngodon and Aplectana (Yamaguti 1961). Neopharyngodon gekko was reported from Indian lizard (Chakravorty \& Bhaduri 1948) and Neopharyngodon sp. was recorded in toads and frogs from Bangladesh (Ahmed et al. 2006a \& 2006b, Begum et al. 1996, Begum et al. 2012). However, this nematode species has not been reported in reptiles of Nepal. In this study, we examined the wall lizards (Gecko) and reported the prevalence and intensity of nematode parasite Neopharyngodon sp. with its characteristics for the first time from Nepal.

\section{MATERIALS AND METHODS}

Twenty five wall lizards including fifteen $H$. brookii brooki and ten $H$. Platyurus were collected and identified on the basis of morphological characteristics (Shah and Tiwari 2004) from Kirtipur, Nepal. H. brookii brooki have some basic traits such as light brown or greyish on above dark, strip along the side of the head and white dirty ventral portion (Shah \&Tiwari 2004). H. platyurus have grey or greyish brown dorsal, dirty or yellow white ventral portion, tail flat and seldom red (Shah \& Tiwari 2004). The wall lizards were collected using net from human settlements particularly, dining room, study room, bedroom etc. The live animals were kept in cloth bag or transparent jar with sufficient ventilation. Each lizard was anaesthetized using chloroform, dissected longitudinally from ventral portion and rectum was thoroughly examined for nematode parasites. Collected parasites were kept in saline solution and parasites were stored in $70 \%$ ethanol and cleared in lactophenol as per the methods described previously (Pun \& Maharjan 2015). The comparisons of morphological traits were done with the help of taxonomic key (Yamaguti 1961). The prevalence and parasitic intensity were determined as follows:

Prevalence $=($ Number of host infected $/$ total number of host examined) $\times 100$

Parasitic intensity $=$ Total number of parasites observed / total number of hosts infected

(Pun \& Maharjan 2016b). 


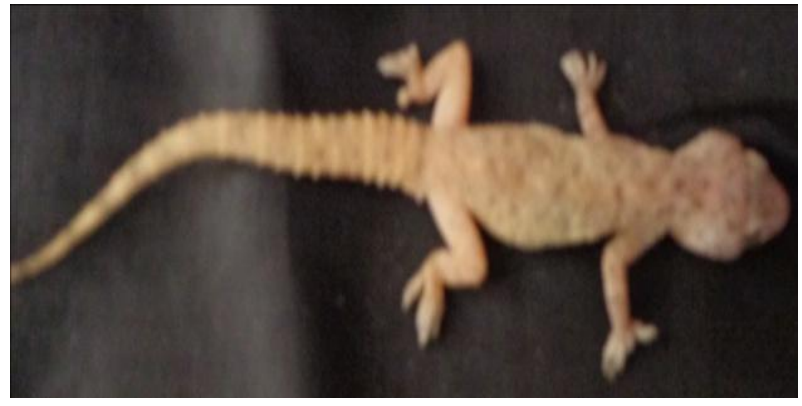

(A)

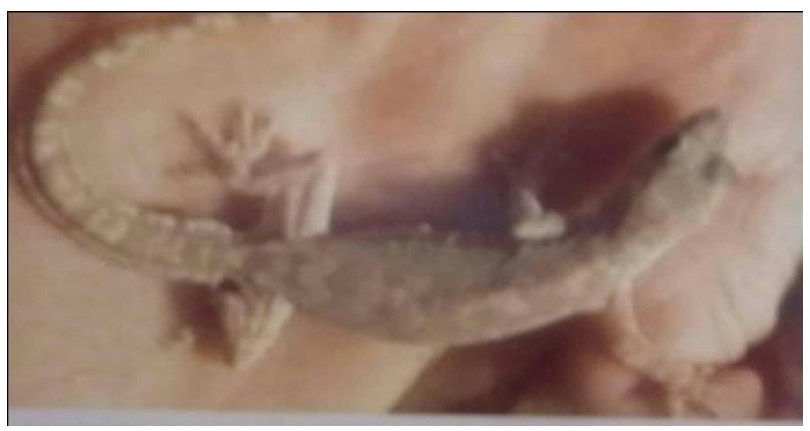

(B)

Fig. 1. A- Hemidactylus brookii brooki, B- Hemidactylus platyurus

\section{RESULTS}

The nematode parasites were collected from the rectum of $H$. brookii brookii and $H$. platyurus. Taxonomic characteristics on the basis of morphometric measurement revealed smaller (1.375-1.5 $\mathrm{mm}$ long by $0.225-0.25 \mathrm{~mm}$ wide) (Fig. 2A) size of the nematodes. They had lateral cuticular ridges, but no membranous flanges. Mouth had two lips. Anterior and posterior extremities were obliquely truncated ventrally and dorsal end was produced into a fine pointed process (Fig. 2B-2D). Oesophagus was $0.35 \mathrm{~mm}$ longer and $0.03 \mathrm{~mm}$ wider (Fig. 2E) and oesophagus bulb was $0.0925 \mathrm{~mm}$ in diameter (Fig. 2F). Tail was pointed with the length $0.52 \mathrm{~mm}$ which is one-third of the whole body length (Fig. 2G). During the study period, only male nematodes were collected, no female nematodes were found for the further identification. The characters observed in these nematodes resembled with the genus Neopharyngodon described earlier with unidentified species.

Neopharyngodon sp had higher prevalence $(80 \%)$ in $H$. platyurus in comparison to $H$. brookii brookii which had $20 \%$ prevalence. The intensity of infection however was comparable among $H$. brookii brookii (4.3) and H. platyurus (4) (Table 1).

Table 1. Prevalence and parasitic intensity of Neopharyngodon sp. male in Hemidactylus brookii brookii and Hemidactylus platyurus.

\begin{tabular}{|c|c|c|c|c|c|c|c|c|c|c|}
\hline $\begin{array}{l}\tilde{\Xi} \\
\sum \\
\Sigma\end{array}$ & 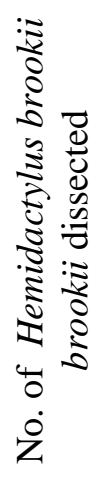 & 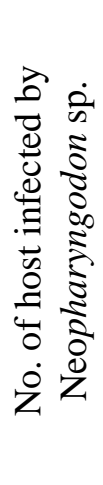 & 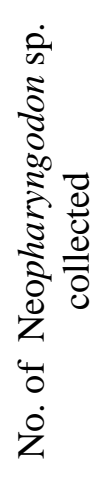 & 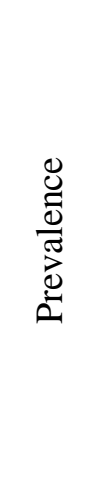 & 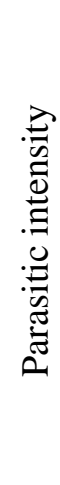 & 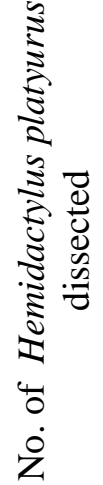 & 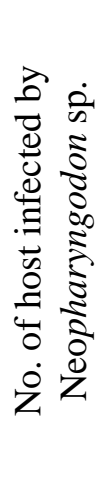 & 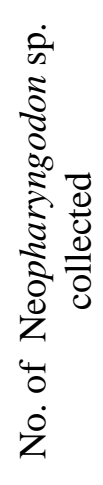 & 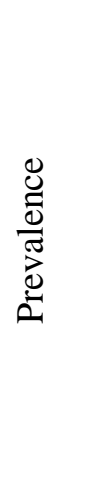 & 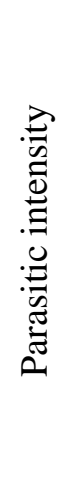 \\
\hline April & 7 & 2 & 3 & \multirow{4}{*}{$20 \%$} & \multirow{4}{*}{4.3} & 2 & 2 & 10 & \multirow{4}{*}{$80 \%$} & \multirow{4}{*}{4} \\
\hline May & 6 & - & - & & & 4 & 2 & 2 & & \\
\hline July & 2 & 1 & 10 & & & 4 & 4 & 20 & & \\
\hline Total & 15 & 3 & 13 & & & 10 & 8 & 32 & & \\
\hline
\end{tabular}



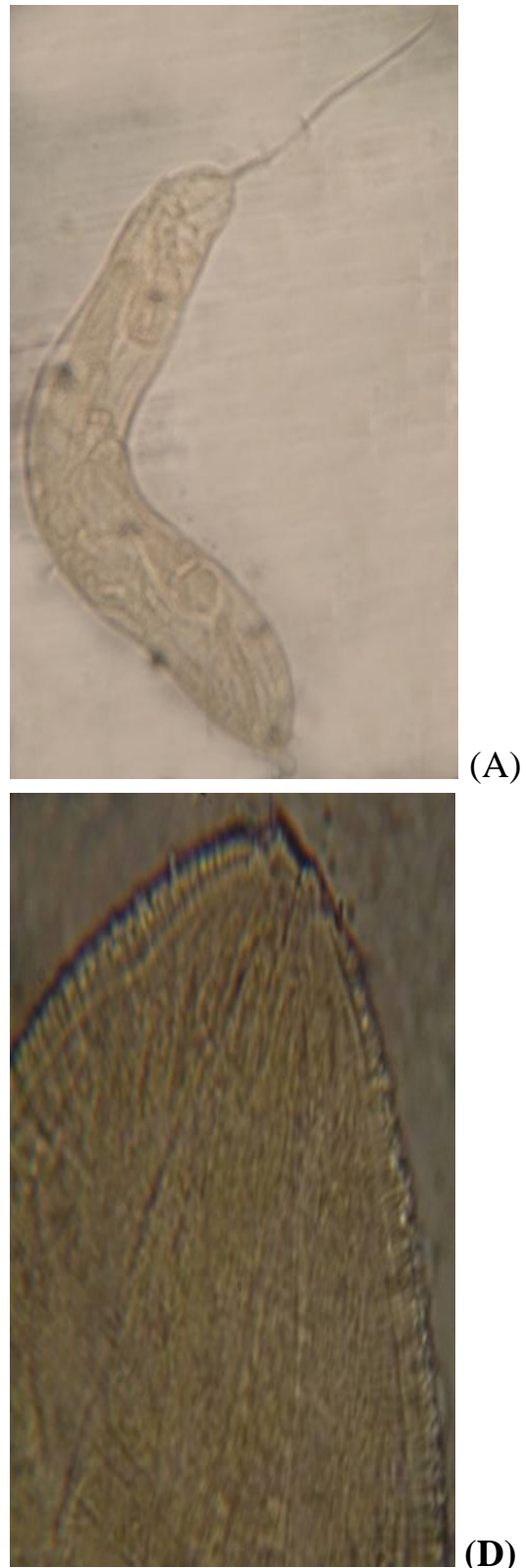

(D)

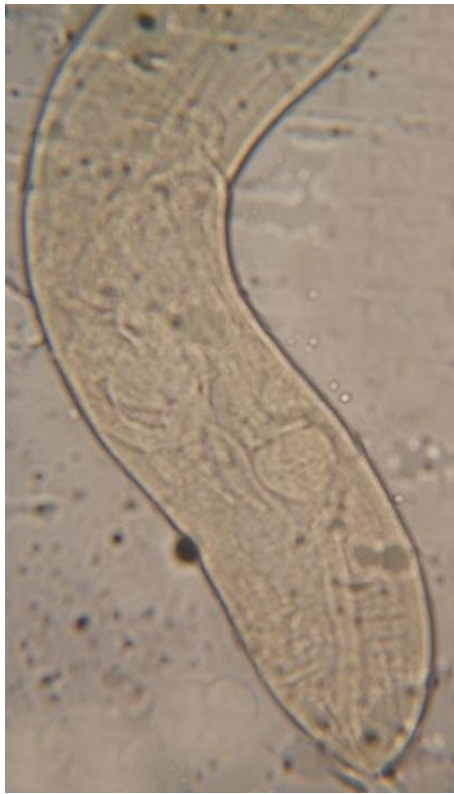

\section{(A)}

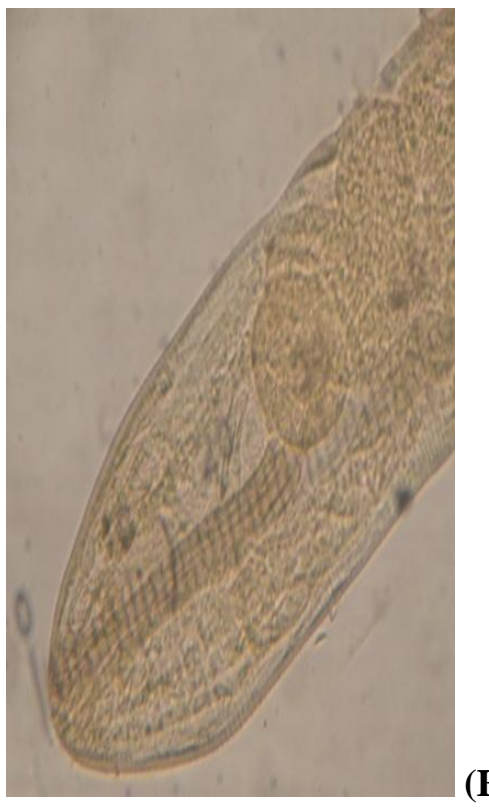

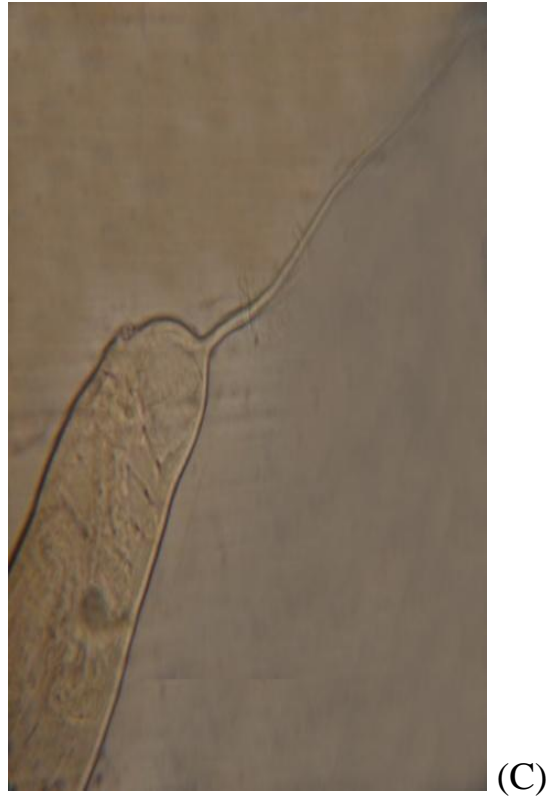

(E)

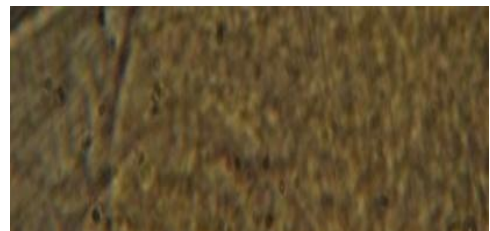
C)

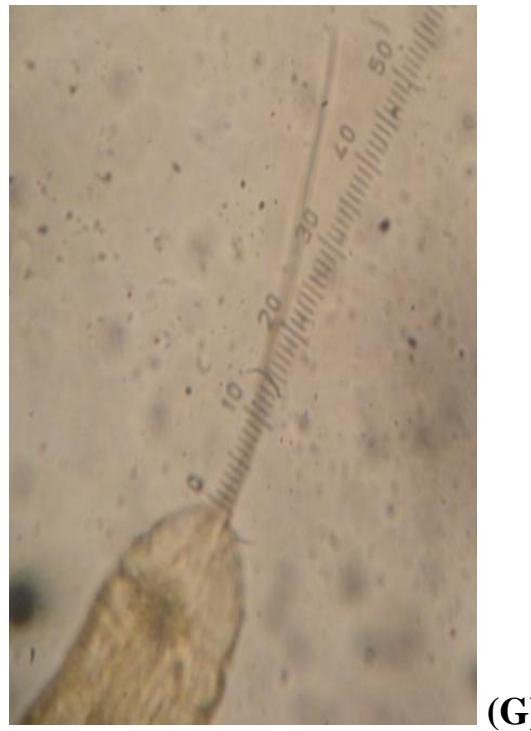

Fig. 2. Neopharyngodon sp. male,

A. Entire adult,

B. Anterior view,

C. Posterior view,

D. Mouth,

E. Oesophagus,

F. Oesophageal bulb,

G. Tail

(G) 


\section{DISCUSSION}

The parasite Neopharyngodon sp. has been recorded from amphibians (Begum \& Banu 2012) and reptiles (Yamaguti 1961) previously. Similar species of nematode parasite has been recorded from Gekko gecko from Calcutta (Chakravorty \& Bhaduri 1948). The Neopharyngodon spp. reported from Bufo melanostictus (Begum \& Banu, 2012) and from reptiles (Yamaguti 1961) had similar characteristics such as small size, two lips, body measurements, oesophagus position and long pointed tail.

According to Begum \& Banu (2012), the prevalence of Neopharyndogon spp in Bufo melanostictus from Bangladesh was $68 \%$ with intensity of infection 24.29. The intensity of infection in present study was lower than that of Begum \& Banu (2012) while the prevalence was lower in $H$. brookii brookii but higher in $H$. platyurus. We reported the nematode parasite Neopharyngodon spp. male for the first time from the wall lizards of Nepal which has physical characteristics similar to those described by others previously with variable prevalence and intensity of infection.

\section{CONCLUSION}

Neopharyngodon sp. male recorded in this study shows the first report from $H$. brookii brookii and $H$. platyurus from Nepal. $H$. platyurus were found highly infected compared to $H$. brookii brookii.

\section{REFERENCES}

Ahmed, A. T. A. and Begum, A. 2006a. A survey of helminth parasites of toad (Bufo melanostictus Schneider, 1799), bullfrog (Hoplobatrachus tigerinus Daudin, 1802) and skipper frog (Euphlyctis cyanophlyctis Schneider, 1799) from Dhaka and Feni districts. Bangladesh Journal of Zoology 34(1): 79-86.

Ahmed, A. T. A. and Begum, A. 2006b. A distribution of helminth parasites in toads and frogs in Bangladesh. Dhaka University Journal of Biological Sciences 15(1): 77-84.

Begum, A., Ahmed, A.T.A. and Zaman, Z. 1996. Incidence of helminth parasites in bullfrog Rana tigrina (Daudin). Dhaka University Journal of Biological Sciences 5(2): 21-28.

Begum, A. and Banu, N. 2012. Sex organal and seasonal differences of helmintho fauna of toad, Bufo melanostictus (Schneider, 1799). Bangladesh Journal of Zoology 40(2): 155-164.

Chakravorty, G. K. and Bhaduri, N.V. 1948. An oxyurid nematode Neopharyngodon gekko, gen. et sp. nov. from the Indian lizard Gekko gecko (Linn.). Proceedings of the Zoological society of Bengal 1(2): 103-107.

Pun, S. K. and Maharjan, M. 2015. New Report of Rhabdias sp. (Nematoda: Rhabdiasidae) from Nepal. Journal of Institute of Science and Technology 20(2), 153-155.

Pun, S. K. and Maharjan, M. 2016a. A new report of Kalicephalus sp. intestinal nematode parasite of Amphiesma stolatum(Reptilia: Colubridae) from Kirtipur, Nepal. Research Journal of Recent Sciences 5 (ISCA 2015), 20-23.

Pun, S. K. and Maharjan, M. 2016b. Aplectana sp., nematode parasite of Bufo stomaticus from Kirtipur, Nepal. Research Journal of Animal, Veterinary and Fishery Sciences 4(5), 1-6.

Shah, K. B. and Tiwari, S. 2004. Herpetofauna of Nepal: A conservation companion. IUCNThe world conservation union (Kathmandu).

Yamaguti, S. 1961. Systema Helminthum. Volume III. The Nematodes of Vertebrates,. Interscience publishers New York, pp1261. 